\title{
Successful Endoscopic Resection of Large Pedunculated Brunner's Gland Hamartoma Causing Gastrointestinal Bleeding Arising from the Pylorus
}

\author{
Yunho Jung ${ }^{\mathrm{a}}$ Il Kwun Chung ${ }^{\mathrm{a}}$ Tae Hoon Lee ${ }^{\mathrm{a}}$ Young Sin Cho ${ }^{\mathrm{a}}$ \\ Yeong Geol Jo ${ }^{a}$ Sang Heum Park ${ }^{a}$ Hyundeuk Cho ${ }^{b}$ Sun Joo Kim ${ }^{a}$ \\ ${ }^{\mathrm{a}}$ Department of Internal Medicine, Division of Gastroenterology, and ${ }^{\mathrm{b}}$ Department of \\ Pathology, Soonchunhyang University College of Medicine, Cheonan, Korea
}

\section{Key Words}

Brunner's gland hamartoma $\cdot$ Hematemesis $\cdot$ Melena $\cdot$ Endoscopic mucosal resection

\begin{abstract}
Brunner's gland hamartoma is a rare benign small bowel neoplasm and most lesions are small and asymptomatic. However, large hamartoma-related obstructive symptoms and hemorrhage related to tumor ulceration manifest as hematemesis or melena. The exact pathogenesis if these lesions is not well known, but they are thought to be frequently associated with Helicobacter pylori infections and chronic pancreatitis. We report the case of a 45-year-old man who presented with melena due to a large pedunculated Brunner's gland hamartoma arising from the pylorus. It was successfully removed by endoscopic mucosal resection with piecemeal technique because of too large tumor size for application of a conventional snare.

(c) 2013 S. Karger AG, Basel
\end{abstract}

\section{Introduction}

Benign small bowel neoplasms are uncommonly encountered. Brunner's gland hamartoma represent $5-10 \%$ of small bowel tumors and occurs most commonly in the fifth and sixth decade of life, with no gender or race predominance. Most of the lesions are small, asymptomatic and detected incidentally [1,2]. Clinical symptoms are caused by obstruction, leading to postprandial pain, and bleeding. The location of the lesion is often at the bulb of the duodenum and the incidence decreases with increasing distance from the pyloric ring

Yunho Jung, MD

Department of Internal Medicine, Division of Gastroenterology

Soonchunhyang University College of Medicine

23-20 Bongmyung-dong, Dongnam-gu

Cheonan-si, Chungcheongnam-do (South Korea)

E-Mail yoonho7575@naver.com 
[3]. In symptomatic patients, Brunner's gland hamartoma can be treated either by endoscopic or surgical excision [4]. We report a case of successful endoscopic removal of a large Brunner's gland hamartoma with gastrointestinal bleeding arising from the pylorus.

\section{Case Report}

A 45-year-old man presented with a 4- or 5-day history of melena. He also presented nausea lasting for 10 days. His medical history was not significant for hypertension or diabetes. On physical examination, he was afebrile with normal vital signs. His abdomen was soft and nontender. Laboratory tests showed his hemoglobin to be $10.2 \mathrm{~g} / \mathrm{dl}$. Esophagogastroduodenoscopy showed a pedunculated ulcerated mass about $50 \mathrm{~mm}$ large arising from the pyloric ring (fig. 1). We tried to pull the tumor into the stomach with a snare to prevent loss of the tumor after resection because the tumor head was located in the bulb of the duodenum. However, the tumor was too big to pass the pyloric ring. Therefore, endoscopic piecemeal mucosal resection was performed in the bulb of the duodenum for pulling out the specimen after resection; it was successfully removed by snare. A snare polypectomy was performed and secured with a clip. The lesion was a well-circumscribed mass of $48 \times 32 \mathrm{~mm}$, with an ulcerated surface and yellowish core (fig. 2). Histological examination of the mass showed Brunner's glands with ducts separated by fibromuscular stroma (fig. 3). After 5 months, follow-up esophagogastroduodenoscopy was performed; there was no evidence of recurrence.

\section{Discussion}

Brunner's glands were first described by Brunner in 1688 [5]. They are branched acinotubular glands located in the submucosa and lined with cuboidal-to-columnar clear cells in the glands and cuboidal cells in the duct [6]. The distinction between Brunner's gland hyperplasia and Brunner's gland hamartomas is arbitrary. Brunner's gland hyperplasia is considered if the lesion is $<5 \mathrm{~mm}$ in size, either solitary or multiple, and Brunner's gland hyperplasia if it is $>5 \mathrm{~mm}$, contrary to Brunner's gland hyperplasia [7]. The symptomatic features of Brunner's gland hamartoma can be divided into two categories, namely hemorrhagic and obstructive type. The hemorrhagic manifestations due to ulceration or erosion of the tumor are melena, fatigue, anemia and rarely hematemesis [8]. Obstruction occurs when the hyperplasia is diffuse or a single adenoma grows too large, causing epigastric bloating, pain, nausea, vomiting and weight loss [9]. Patients with tumor-related obstructive complications tend to have hamartomas $>2 \mathrm{~cm}$ [10]. In our case, the size of tumor was about $5 \mathrm{~cm}$. The patient presented hemorrhagic manifestation such as 4 or 5 days of melena and obstruction symptoms like nausea. Uncommon presentations include obstructive jaundice, biliary fistula, recurrent pancreatitis or intussusception [5]. Most Brunner's gland hamartomas are located in the duodenal bulb (57\%), but they may also be found in the second $(27 \%)$ or third (7\%) parts of the duodenum and are rarely detected in the pyloric canal $(5 \%)$, jejunum (2\%) or proximal ileum (2\%) [2]. Most tumors are 1-2 cm in size, however, tumors sized about $9 \mathrm{~cm}$ are also reported [11]. In our case the tumor was originated from the pylorus, which seemed to be a rare location, and the size was bigger than usual.

The exact pathogenesis is not well known, but many etiologies were proposed for the pathogenesis of Brunner's gland tumors, such as local irritation, parasympathetic activity, chronic pancreatitis, Helicobacter pylori infection and Billroth II reconstruction [12]. An 
Jung et al.: Successful Endoscopic Resection of Large Pedunculated Brunner's Gland Hamartoma Causing Gastrointestinal Bleeding Arising from the Pylorus

accurate diagnosis can be difficult. The differential diagnosis usually includes leiomyomas, adenomas, lipomas, Peutz-Jeghers syndrome, adenocarcinomas, carcinoids, lymphomas, leiomyosarcomas, pancreatic or ampullary neoplasm [13].

Asymptomatic small Brunner gland hamartomas usually require no treatment. However, treatment is suggested for larger tumors, even if asymptomatic, to prevent development of complications such as bleeding or obstruction. Endoscopic resection is the treatment of choice if the tumor is pedunculated and relatively small, whereas larger-sized lesions require open surgical resection. Recurrence after endoscopic or surgical excision has not been reported. In our case, we decided to resect endoscopically because of melena, obstructive symptoms and pedunculated type. However, the tumor was too big to pass through the pylorus and to be resected with conventional snare at a time; therefore we decided to do endoscopic piecemeal resection. After applying endoclips to prevent bleeding, the tumor was successfully resected by two pieces with a snare, and there was no evidence of recurrence 5 months after resection.

\section{Acknowledgement}

This work was supported by the Soonchunhyang University Research Fund.

\section{Disclosure Statement}

None of the authors has identified a conflict of interest.

\section{References}

1 Gokhale U, Pillai GR: Large Brunner's gland hamartoma: a case report. Oman Med J 2009;24:41-43.

$\checkmark 2$ Rocco A, Borriello P, Compare D, De Colibus P, Pica L, Iacono A, Nardone G: Large Brunner's gland adenoma: case report and literature review. World J Gastroenterol 2006;12:1966-1968.

-3 Levine JA, Burgart LJ, Batts KP, Wang KK: Brunner's gland hamartomas: clinical presentation and pathological features of 27 cases. Am J Gastroenterol 1995;90:290-294.

4 Lin JC, Hsieh TY, Chan DC: Brunner's gland hamartoma. Gastroenterology 2009;137:789, 1187.

5 Abbass R, Al-Kawas FH: Brunner gland hamartoma. Gastroenterol Hepatol (N Y) 2008;4:473-475.

6 Woharndee P, Sornmayura P, Bunyaratvej S: Brunner's gland adenoma: a report of two cases. J Med Assoc Thai 2005;88:841-844.

7 Patel ND, Levy AD, Mehrotra AK, Sobin LH: Brunner's gland hyperplasia and hamartoma: imaging features with clinicopathologic correlation. AJR Am J Roentgenol 2006;187:715-722.

-8 Chattopadhyay P, Kundu AK, Bhattacharyya S, Bandyopadhyay A: Diffuse nodular hyperplasia of Brunner's gland presenting as upper gastrointestinal haemorrhage. Singapore Med J 2008;49:81-83.

-9 Gao YP, Zhu JS, Zheng WJ: Brunner's gland adenoma of duodenum: a case report and literature review. World J Gastroenterol 2004;10:2616-2617.

10 de Nes LC, Ouwehand F, Peters SH, Boom MJ: A large Brunner's gland hamartoma causing gastrointestinal bleeding and obstruction. Dig Surg 2007;24:450-452.

-11 So CS, Jang HJ, Choi YS, Koh DH, Choi MH, Kae SH, Min SJ, Lee J: Giant Brunner's gland adenoma of the proximal jejunum presenting as iron deficiency anemia and mimicking intussusceptions. Clin Endosc 2013;46:102-105.

12 Mumtaz R, Shah IA, Ramirez FC: Brunner's gland hamartoma simulating a pancreatic mass with duodenal obstruction. Gastrointest Endosc 2002;56:932-934.

13 Block KP, Frick TJ, Warner TF: Gastrointestinal bleeding from a Brunner's gland hamartoma: characterization by endoscopy, computed tomography, and endoscopic ultrasound. Am J Gastroenterol 2000;95:1581-1583. 


\section{Case Reports in \\ Gastroenterology}

\begin{tabular}{l|l}
\hline Case Rep Gastroenterol 2013;7:304-307 \\
\hline DOI: 10.1159/000354138 & $\begin{array}{l}\text { ○ 2013 S. Karger AG, Basel } \\
\text { www.karger.com/crg }\end{array}$ \\
\hline
\end{tabular}

Jung et al.: Successful Endoscopic Resection of Large Pedunculated Brunner's Gland Hamartoma Causing Gastrointestinal Bleeding Arising from the Pylorus

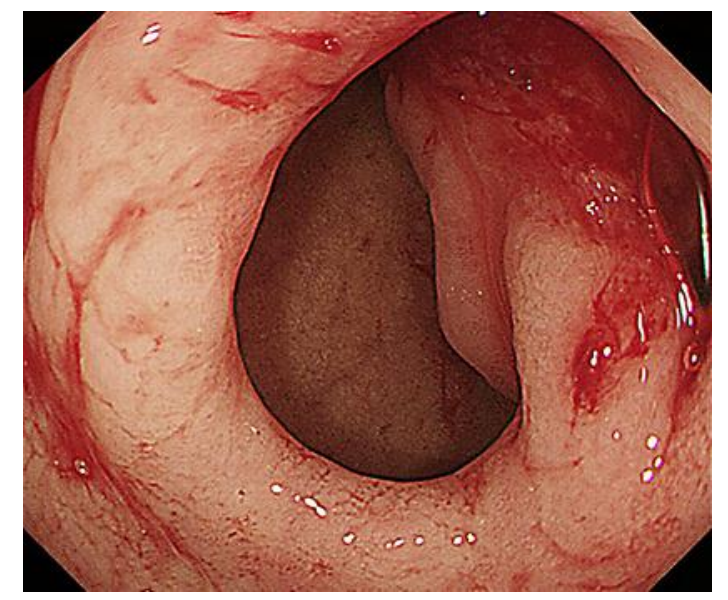

Fig. 1. Esophagogastroduodenoscopy showed a large pedunculated mass arising from the pyloric ring.

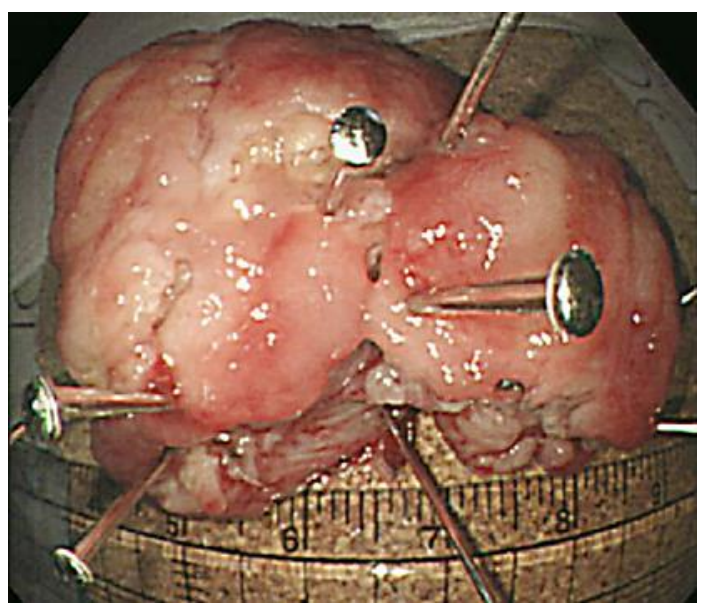

Fig. 2. A mass about $5 \mathrm{~cm}$ in size was pinned on flat cork plates immediately following resection.

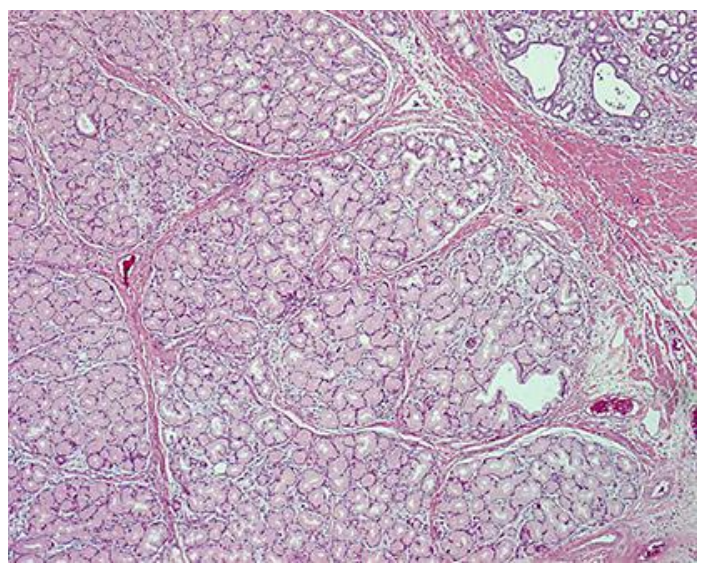

Fig. 3. Hyperplastic lobules of proliferated Brunner's glands separated by fibrous septa (H\&E, $\times 40)$. 